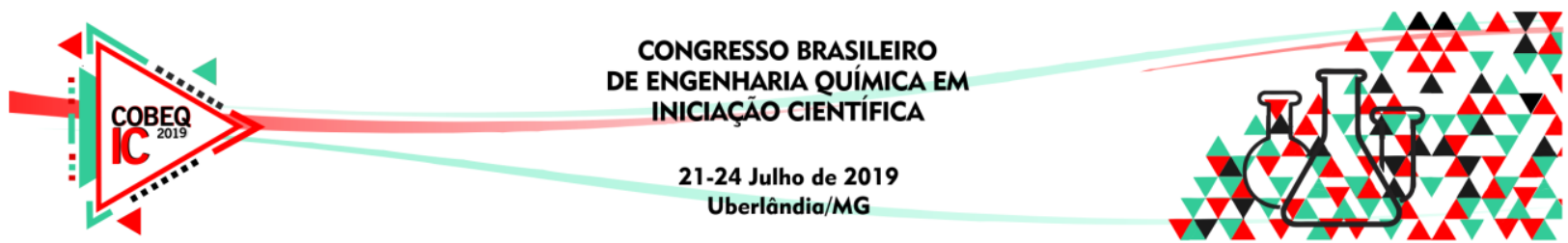

\title{
COMPARAÇÃO ENTRE O DESEMPENHO DO EXTRATO DE TANINO DE ACÁCIA NEGRA E O DA QUITOSANA COMO AUXILIAR DE CLARIFICAÇÃO DE CALDO DE CANA
}

\author{
R. B. DA SILVA ${ }^{1}$, I. R. LEITE ${ }^{1}$, M. M. LUIZE $^{1}$ e R. D. BARBOSA ${ }^{2}$ \\ ${ }^{1}$ Centro Universitário da Fundação Educacional de Barretos, Faculdade de Engenharia \\ Química \\ ${ }^{2}$ Universidade Estadual Paulista, Departamento de Engenharia e Tecnologia de Alimentos \\ E-mail para contato: inacioramosleite@yahoo.com.br
}

\begin{abstract}
RESUMO - A clarificação do caldo de cana é uma das etapas mais importantes do processo de fabricação de açúcar com efeitos sobre a qualidade e rendimento do produto final. Atualmente, na indústria brasileira, está consolidada a utilização de ácido fosfórico e do gás anidrido sulfuroso, este último, contudo, sempre foi muito questionado por questões ambientais e por causar reações adversas à saúde em pessoas sensíveis aos sulfitos. Por essas razões, novos agentes de clarificação vêm sendo estudados como possíveis opções. Neste contexto, este trabalho se propôs a investigar o desempenho do extrato de tanino de Acácia Negra e da quitosana, dois compostos naturais, na clarificação de caldo voltada para fabricação de açúcar. Os resultados obtidos mostraram que tanto o tanino como a quitosana foram capazes de diminuir a cor e a turbidez do caldo tratado, apresentando resultados melhores do que os observados nos tratamentos convencionais realizados neste estudo. A atuação do tanino como auxiliar de clarificação resultou em maior remoção de cor (34\%) quando comparada com a remoção observada nos tratamentos realizados com a quitosana $(4,5 \%)$. Por outro lado, obteve-se maior remoção de turbidez utilizando-se a quitosana $(99,92 \%)$ do que o tanino $(93,3 \%)$.
\end{abstract}

\section{INTRODUÇÃO}

O Brasil é o maior produtor e exportador de açúcar do mundo, representando cerca de $20 \%$ do açúcar produzido e $40 \%$ do açúcar exportado, conforme dados da FAOSTAT (Food and Agriculture Organization of the United Nations, 2019). Na fabricação deste produto, o processo de clarificação do caldo de cana é uma das etapas mais importantes, posto que uma boa clarificação surte efeitos altamente benéficos na qualidade e rendimento do produto final. Grande parte dos processos de fabricação de açúcar em operação no Brasil, principalmente aqueles voltados à produção de açúcar branco, realizam a clarificação por meio de processos de separação auxiliados por insumos químicos alcalinos, oxidantes e agentes floculantes, os quais são fundamentais para a obtenção de um açúcar de qualidade (Rein, 2007). Na prática, está consolidada na indústria brasileira a utilização de ácido fosfórico e do gás anidrido sulfuroso como auxiliares do processo de clarificação (Albuquerque, 2011). Caldos com alto teor de $\mathrm{P}_{2} \mathrm{O}_{5}$ clarificam com mais facilidade, pois sua presença precipita parte dos coloides e das matérias corantes presentes no meio (Baikow, 1982; Marques; Marques; Tasso Júnior, 


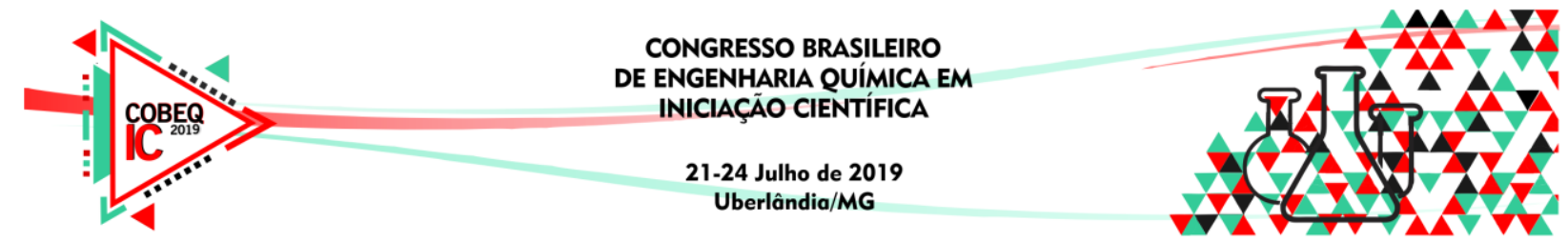

2001). O anidrido sulfuroso, por sua vez, quando absorvido pelo caldo, atua como um forte agente redutor sobre substâncias corantes do caldo, reduzindo sua cor. Além disso, o $\mathrm{SO}_{2}$ inibe a formação de compostos coloridos e aumenta a velocidade de sedimentação nos decantadores (Rodríguez, 2009).

Além dos insumos químicos normalmente utilizados pela indústria açucareira no Brasil, outros agentes vêm sendo estudados e apresentados como possíveis opções. Peróxido de hidrogênio, aluminatos de sódio, ozônio, dióxido de carbono, dentre tantos outros compostos vem sendo testados em laboratório e industrialmente (Albuquerque, 2011; Hamerski; Aquino; Ndiaye, 2011; Madho; Davis, 2008). No entanto, pouco se evoluiu, considerando que o setor açucareiro, em sua grande maioria, encontra-se refém do tradicional processo de sulfitação do caldo para fabricação de açúcar branco (Albuquerque, 2011) que sempre foi muito questionado por causar reações adversas à saúde em pessoas sensíveis aos sulfitos (Favero; Ribeiro; Aquino, 2011).

Nos últimos anos muitos trabalhos relacionados a processos utilizando taninos e quitosana como auxiliar de coagulação e floculação têm sido publicados, ainda que nenhum aplicado ao caldo ou xarope de cana-de-açúcar. Taninos são compostos naturais, com habilidade de se combinar com proteínas, alcaloides e outros polímeros, sendo muito utilizados na indústria coureira, no tratamento de água e efluentes, entre tantas outras aplicações. Seu bom desempenho como auxiliar de coagulação e floculação em diferentes áreas tem chamado a atenção. A quitosana pode ser obtida por meio de desacetilação da quitina por meio de álcalis. Este polímero desperta elevado interesse econômico, visto que a quitina é o segundo polímero mais abundante na natureza. Em decorrência disso, uma série de trabalhos tem sido realizado empregando a quitosana como adsorvente para remoção de metais, corantes e fenóis de efluentes industriais (Juang et al., 1997; Rhee et al., 1998; Kimura et al., 1999). Uma outra aplicação para este polímero é atuar como polieletrólito catiônico na coagulação da matéria coloidal de água potável (Huang; Chen, 1996 apud Spinelli, 2001).

Neste contexto, esta pesquisa teve por objetivo avaliar o extrato de tanino de Acácia Negra e a quitosana, dois compostos naturais, como agentes auxiliares de clarificação do caldo de cana. Este estudo avaliou os resultados obtidos na aplicação destes insumos em diferentes dosagens através de experimentos de bancada, e seus desempenhos foram comparados a fim de se determinar o que apresentou melhor resultado quanto a remoção de cor e turbidez do caldo.

\section{MATERIAIS E MÉTODOS}

\subsection{Matéria-Prima e Auxiliares de Clarificação}

Caldo de cana: Os ensaios de clarificação foram realizados com caldo extraído em modelo do tipo engenho (Engenho B12 Alto Inox, fabricado por Botini®). A cana, previamente limpa, foi moída com casca, e o caldo obtido foi resfriado e utilizado no dia seguinte. Foram utilizados dois lotes de caldo, sendo um deles para a clarificação com extrato de tanino, e o outro para a clarificação com a quitosana. 


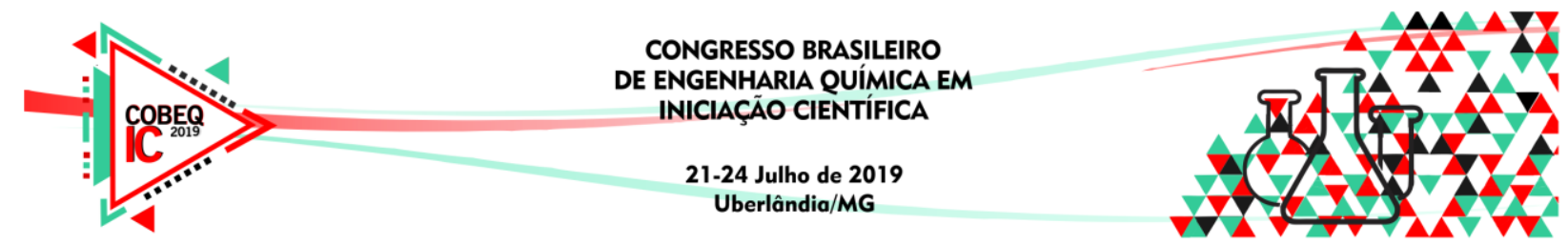

Agentes clarificantes: Utilizou-se ácido fosfórico com 85\% de pureza analítica (Synth, Diadema, SP) no preparo de solução aquosa de ácido fosfórico $10 \%$ (v/v). O leite de cal utilizado na etapa de caleagem foi preparado a partir de hidróxido de cálcio $\left(\mathrm{Ca}(\mathrm{OH})_{2}\right)$ de pureza analítica (Synth, Diadema, SP) e água deionizada, na concentração de $86 \mathrm{~g} / \mathrm{L}$ (7 ${ }^{\circ}$ Baumé). Utilizou-se o floculante Flonex 9076 SI, fornecido pela Skills Química (Guarulhos, $\mathrm{SP}$ ), preparado a $0,5 \mathrm{~g} / \mathrm{L}$ com tempo de hidratação de 150 minutos. O extrato de tanino de Acácia Negra utilizado foi fornecido pela Tanac (Montenegro, RS) e preparado a $50 \mathrm{~g} / \mathrm{L}$ com 60 minutos de leve agitação. A solução de quitosana foi preparada a uma concentração de 10 g/L em solução de ácido acético 5\% (v/v), com tempo de agitação de 5 horas para diluição completa.

\subsection{Procedimento para Clarificação e Análises}

Ensaios de clarificação de caldo: Ajustou-se o teor de sólidos solúveis do caldo para 16,5 ${ }^{\circ}$ Brix, valor médio apresentado nos processos de fabricação de açúcar (Rein, 2007). Em seguida, realizou-se a fosfatação dosando-se $100 \mathrm{ppm}$ de $\mathrm{P}_{2} \mathrm{O}_{5}$. Logo após, nos ensaios utilizando-se o extrato de tanino, foram adotadas as dosagens de 0, 300, 400 e 500 ppm, valores selecionados com base em resultados obtidos em trabalhos anteriores (Leite, 2019). Os caldos tratados com quitosana receberam as dosagens de 0, 300, 450 e 600 ppm, estabelecidas em ensaios preliminares. Para a caleagem, adicionou-se leite de cal até atingir o pH 7,3. Aqueceu-se o caldo até a ebulição, por meio de resistência elétrica, sob agitação, mantido nesta temperatura por 2 minutos. Em um béquer, foi adicionada, previamente, a dosagem de $3 \mathrm{ppm}$ de floculante e, em seguida, $1.000 \mathrm{~mL}$ de caldo em ebulição foram transferidos para este recipiente tomando o cuidado de adicioná-lo pelas paredes do mesmo, evitando-se a aeração. Após a floculação, o conteúdo do béquer foi transferido para uma proveta tomando os mesmos cuidados para evitar a aeração. Após 20 minutos, o sobrenadante foi retirado para ser analisado quanto a cor e turbidez conforme metodologia proposta pelo Manual de Controle Químico da Fabricação de Açúcar do Centro de Tecnologia Canavieira (CTC, 2011). Estes métodos analíticos, por sua vez, baseiam-se nas metodologias recomendadas pela ICUMSA - International Commission for Uniform Methods of Sugar Analysis.

\section{RESULTADOS E DISCUSSÃO}

A qualidade do caldo clarificado obtido nos ensaios de clarificação com extrato de tanino e quitosana foi avaliada com base na cor e turbidez (Tabela 1). O caldo bruto utilizado na clarificação com extrato de tanino apresentou 15.010 UI de cor e 129,6 NTU de turbidez, enquanto o caldo empregado na clarificação com a quitosana apresentou cor de 19.960 UI e turbidez de 518 NTU.

O extrato de tanino como auxiliar de clarificação proporcionou redução na cor para valores entre 9870 e 10.136 UI, com remoção de 32,3 a 34\%, enquanto o caldo tratado sem tanino (0 ppm), apresentou $23,8 \%$ de cor removida. Para a turbidez, observou-se queda para valores entre 8,7 e 14,5 NTU, o que representa remoção de 88,8 a 93,3\%. O resultados mostraram que o aumento da dosagem de tanino aumentou a remoção de turbidez até a dosagem de $400 \mathrm{ppm}$. A utilização da quitosana como auxiliar de clarificação proporcionou redução na cor para valores entre 19.061 e 19.261 UI, com remoção de 3,5 a 4,5\%. Para a 


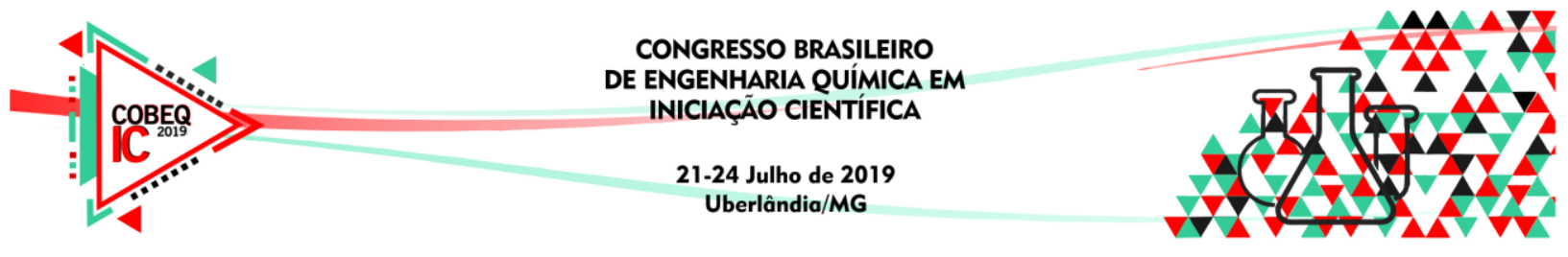

turbidez, observou-se queda para valores entre 0,43 e 1,75 NTU, o que representa remoção de 99,66 a 99,92\%. Com base nos resultados, nota-se que a aplicação do extrato de tanino como auxiliar de clarificação se mostrou mais efetiva na remoção de cor, enquanto a quitosana apresentou resultados melhores quanto ao percentual de remoção de turbidez.

Tabela 1 - Resultados para cor e turbidez obtidos nos ensaios de clarificação.

\begin{tabular}{c|c|c|c|c}
\hline $\begin{array}{c}\text { Tanino } \\
(\mathrm{ppm})\end{array}$ & $\begin{array}{c}\text { Cor } \\
(\mathrm{UI})\end{array}$ & $\begin{array}{c}\text { Remoção } \\
\text { de cor } \\
(\%)\end{array}$ & $\begin{array}{c}\text { Turbidez } \\
(\mathrm{NTU})\end{array}$ & $\begin{array}{c}\text { Remoção de } \\
\text { turbidez } \\
(\%)\end{array}$ \\
\hline \hline 0 & 11.437 & 23,8 & 94,1 & 27,4 \\
\hline 300 & 9.904 & 33,7 & 14,5 & 88,8 \\
\hline 400 & 9.870 & 34,0 & 9,1 & 93,0 \\
\hline 500 & 10.136 & 32,3 & 8,7 & 93,3 \\
\hline $\begin{array}{c}\text { Quitosana } \\
(\text { ppm) }\end{array}$ & Cor & $\begin{array}{c}\text { Remoção } \\
\text { de cor } \\
(\%)\end{array}$ & $\begin{array}{c}\text { Turbidez } \\
(\mathrm{NTU})\end{array}$ & $\begin{array}{c}\text { Remoção de } \\
\text { turbidez } \\
(\%)\end{array}$ \\
\hline 0 & $(\mathrm{UI})$ & 0 & 11,40 & 97,80 \\
\hline 300 & 19.960 & 3,5 & 1,22 & 99,76 \\
\hline 450 & 19261 & 4,5 & 1,75 & 99,66 \\
\hline 600 & 19.061 & 4 & 0,43 & 99,92 \\
\hline
\end{tabular}

Os resultados obtidos no presente estudo demonstram bom desempenho do extrato de tanino na remoção de cor e turbidez quando comparados com processos de clarificação alternativos citados na literatura. Embora a utilização da quitosana tenha proporcionado menor remoção de cor, sua remoção de turbidez foi maior do que a de outros processos de clarificação, cujos resultados vem sendo publicados nos últimos anos. Hamerski, Aquino e Ndiaye (2011), realizando ensaios de clarificação de caldo por carbonatação, obtiveram seus melhores resultados de remoção de turbidez aplicando o processo de carbonatação em pH 9,0, alcançando $88,56 \%$ de remoção de turbidez. Seus melhores resultados para remoção de cor foram obtidos em $\mathrm{pH} 8,0$, condição em que se removeu $66,57 \%$ da cor do caldo. Moreno, Oliveira e Barros (2012), estudando a clarificação de caldo de cana com a adição de 60 ppm de policloreto de alumínio, como agente auxiliar de clarificação, e, caleagem (com hidróxido de cálcio) realizada a $65^{\circ} \mathrm{C}$ até $\mathrm{pH} 8,0$, proporcionou uma redução de $78,3 \%$ na turbidez e $46,7 \%$ na cor. Pulzatto (1995), em estudo da ação conjunta de $\mathrm{P}_{2} \mathrm{O}_{5}$ e $\mathrm{SO}_{2}$ na clarificação de caldo de cana, observou redução de $27,9 \%$ de cor e $43,7 \%$ de turbidez clarificando caldo bruto com teor natural de $80 \mathrm{mg} \mathrm{P}_{2} \mathrm{O}_{5} / \mathrm{L}$ utilizando dosagem de $100 \mathrm{mg} \mathrm{SO} / 2$ de caldo.

\section{CONCLUSÕES}

Os resultados obtidos mostraram que o caldo clarificado com o auxílio do extrato de tanino de Acácia Negra apresentou valores de cor significativamente melhores do que os alcançados pela quitosana e por outros tratamentos citados na literatura, incluindo tratamentos convencionais. Nas condições estudadas, a quitosana apresentou maior percentual de remoção de turbidez que o extrato de tanino. Propõe-se a continuação do estudo visando avaliar outras condições de aplicação $\left(\mathrm{pH}\right.$, dosagem de floculante, teor de $\left.\mathrm{P}_{2} \mathrm{O}_{5}\right)$ para o tanino e a quitosana na clarificação de caldo de cana. 


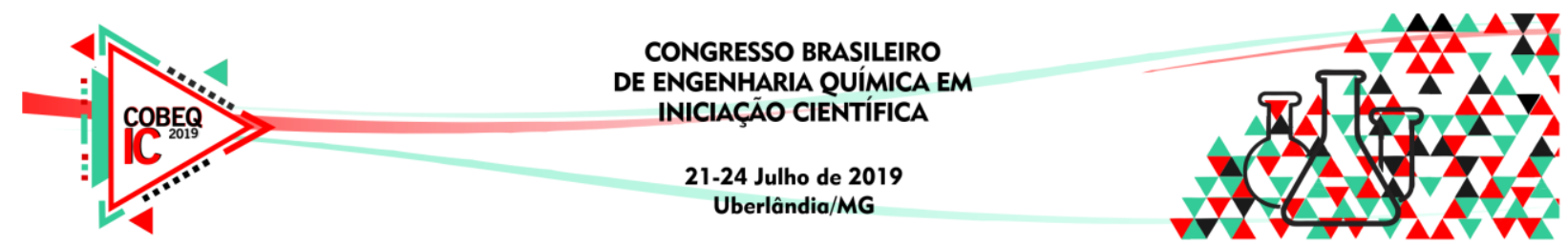

\section{REFERÊNCIAS}

ALBUQUERQUE, F. M. Processo de fabricação do açúcar. 3. ed. Recife: Ed. Universitária da Universidade Federal de Pernambuco, 2011. 447 p.

BAIKOW, V. E. Manufacture and refining of raw cane sugar. 2. ed. Amsterdam: Elsevier, 1982. $588 \mathrm{p}$.

CTC. Manual de controle químico da fabricação de açúcar. Piracicaba, 2011.

FAOSTAT. Data. FAOSTAT. Disponível em: < http://www.fao.org/faostat/en/\#data >. Acesso em: 27 jan. 2019.

FAVERO, D. M.; RIBEIRO, C. S. G.; AQUINO, A. D. Sulfitos: importância na indústria alimentícia e seus possíveis malefícios à população. Segurança Alimentar e Nutricional, v.18, n.1, p. 11-20, 2011.

HAMERSKI, F.; AQUINO, A. D.; NDIAYE, P. M. Clarificação do caldo de cana-de-açúcar por carbonatação - ensaios preliminares. Acta Scientiarum. Technology, Maringá, v.33, n.3, p. 337-341, 2011.

JUANG, R. S.; TSENG, R. L., WU, F. C. J. Adsorption Behavior of Reactive from Aqueos Solution on Chitosan. Chem. Tech. Biotechnol, v. 70, p. 391, 1997.

KIMURA, I. Y.; GONÇALVES, A. C.; STOLBERG, J.; LARANJEIRA, M. C. M.; FÀVERE, V. T. Efeito do $\mathrm{pH}$ e do tempo de contato na adsorção de corantes reativos por microesferas de quitosana. Polímeros: Ciência e Tecnologia, v. 65, p. 1-7, 1999.

LEITE, I. R. Avaliação e otimização do desempenho do extrato de tanino de Acácia Negra na clarificação de caldo e xarope de cana para fabricação de açúcar. 2019. 172 f. Tese (Doutorado em Engenharia e Ciência de Alimentos) - Instituto de Biociências, Letras e Ciências Exatas, Universidade Estadual Paulista, São José do Rio Preto, 2019.

MARQUES, M. O.; MARQUES, T. A.; TASSO JÚNIOR, L. C. Tecnologia do açúcar: Produção e Industrialização da Cana-de-Açúcar. Jaboticabal: Funesp, 2001. 170 p.

MADHO, S.; DAVIS, S. B. Review of proven technologies available for the reduction of raw sugar colour. Proc. S. Afr. Sug. Technol. Ass., v. 81, p. 165 - 183, 2008.

MORENO, R. M. C.; OLIVEIRA, R. C.; BARROS, S. T. D. Comparison between microfiltration and addition of coagulating agents in the clarification of sugar cane juice. Acta Scientiarum. Technology, Maringá, v.34, n.4, p.413-419, Oct - Dec. 2012.

PULZATTO, M. E. Ação do fósforo e enxofre na clarificação por sulfo-defecação do caldo de cana-de-açúcar. 1995. 89 f. Dissertação (Mestrado) - Faculdade de Engenharia de Alimentos, Universidade Estadual de Campinas, Campinas, 1995. 


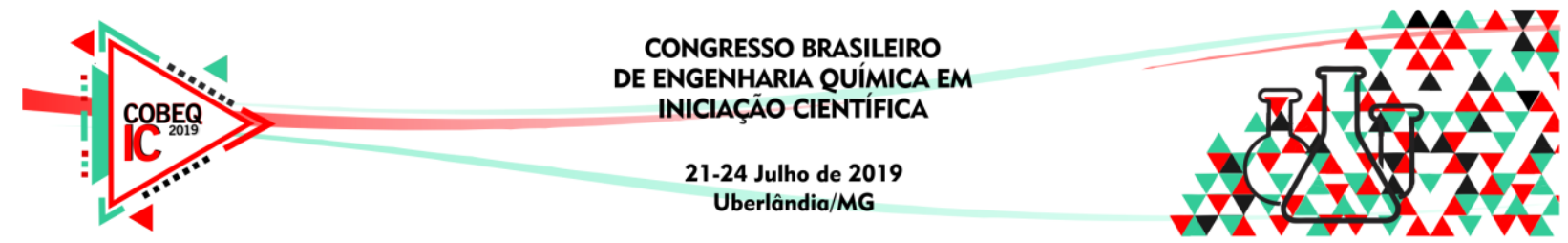

REIN, P. Cane Sugar Engineering. Berlim: Bartens, 2007.

RHEE, J. S.; JUNG, M. W.; PAENG, K. J. Evaluation of Chitin and Chitosan as a Sorbent for the Preconcentration of Phenol and Chlorophenols in Water. Analytical Sciences, v. 14, p. $1089,1998$.

SPINELLI, V. A.; SENS, M. L.; FÁVERE, V. T. Quitosana, polieletrólito natural para o tratamento de água potável. In: Congresso Brasileiro de Engenharia Sanitária e Ambiental, n. 21, 2001, cidade: ABES.I-097 